PONENCIA II

AGUA Y AGRICULTURA: TRANSFORMACIONES RECIENTES, PROBLEMAS MEDIOAMBIENTALES Y SOCIOECONÓMICOS 


\title{
AGUA Y AGRICULTURA: TRANSFORMACIONES RECIENTES, PROBLEMAS AMBIENTALES Y SOCIOECONÓMICOS
}

\author{
Antonio GIL OLCINA \\ Instituto Universitario de Geografía \\ Universidad de Alicante
}

El extraordinario crecimiento de la demanda de agua durante esta segunda mitad del siglo viene motivado por el fuerte aumento de las necesidades de dicho recurso para usos urbanos y turísticos, industriales y, sobre todo, agrícolas. En efecto, el $80 \%$ de la demanda total y el $90 \%$ del consumo real tienen destino agrícola; según la Memoria Anexa al Anteproyecto del Plan Hidrológico Nacional, dichos porcentajes equivalen a $24.245 \mathrm{hm}^{3}$ anuales, de los cuales las aguas subterráneas suponen 4.364 $\mathrm{hm}^{3}(18 \%)$.

Se estima que las aguas fluyentes sólo podrían ser aprovechadas en el $8 \%$, volumen que no cubriría más allá del $30 \%$ de la demanda. De ahí la singular transcendencia del millar de grandes reservorios, construidos en su casi totalidad desde 1926, y sobre todo a partir de 1950, cuyos vasos totalizan en torno a $50.000 \mathrm{hm}^{3}$. Este nutrido conjunto de pantanos ha producido una intensa y generalizada alteración de los regímenes fluviales, al extremo que muchos de ellos han sido invertidos, al realizarse los desembalses más copiosos en estío (PÉREZ PUCHAL, 1967). Recordemos asimismo las conexiones intercuencas ejecutadas, en particular el trasvase TajoSegura, y las transferencias múltiples previstas, auténtico nudo gordiano del Plan Hidrológico Nacional (GIL OLCINA, 1995).

Algunos cursos fluviales, y ejemplo prototípico constituye el Segura (MELGAREJO, 1995), son objeto de un aprovechamiento, por exhaustivo, excesivo. Poco margen queda, pues, para el llamado caudal ecológico o débito ambiental, sobre el que, significativamente, se ha pronunciado con una serie de cautelas, como no podría ser de otro modo, el Proyecto de Directrices del Plan Hidrológico de la Confederación Hidrográfica del Segura (CONFEDERACIÓN HIDROGRÁFICA DEL SEGURA, 1992), enfatizando que, si lo permiten la ordenación de los recursos de la cuenca, las transferencias foráneas y si, en definitiva, una serie de demandas pueden ser atendidas, dicho uso debe figurar, tras el abastecimiento de poblaciones, en segundo lugar; si ello no fuera posible, ese segundo puesto se mantendría, entonces, para el que 
resultase estrictamente necesario. La mengua no ha sido sólo de caudal, sino también de calidad, a causa de contaminaciones puntuales y difusas sumamente dañinas, que han tornado el recurso en desecho. Sirva como muestra expresiva, que no mera anécdota, la visita, tiempo atrás, a la estación que eleva a las lagunas del Hondo (Crevillente), para su distribución por la Comunidad General de Riegos de Levante (Margen Izquierda), aguas muertas de los azarbes. En verdad, estas aguas distaban mucho de ser incoloras o terrosas, su tonalidad era tan intensamente oscura que se requería todo un acto de fe para admitir que aquel líquido era agua; por supuesto, no resultaba inodora, y presumo que tampoco insípida. Como directa consecuencia, el interesante biotopo que constituyen los dos reservorios acondicionados en El Hondo ha sufrido una gravísima degradación en los últimos seis lustros, que se ha evidenciado de manera bien palpable en la pesca de anguilas, cuyo volumen de captura se ha reducido a la veintava parte de lo que era a comienzos de los años sesenta. Y situaciones similares o próximas se dan por doquier, con una eutrofización de las aguas superficiales a la que no es ajena, sino todo lo contrario, la contaminación difusa originada por el empleo masivo de abonos inorgánicos y productos fitosanitarios en agricultura.

El menoscabo de las aguas hipogeas no cede en gravedad al de las aguas superficiales. En efecto, la movilización masiva de recursos subterráneos mediante la difusión de bombas con eje vertical y electrobombas sumergidas, proceso al que se debe sustancialmente la fuerte expansión del regadío en los últimos treinta y cinco años, ha originado casos frecuentes de sobreexplotación, con una amplia gama de secuelas, entre las que descuella la salinización por intrusión marina o aproximación de las perforaciones al Keuper salífero. Resaltemos asimismo el deterior de freáticos por la contaminación difusa, particularmente con un fuerte aporte de nitritos procedentes de abonos inorgánicos.

Unos pocos datos excusan de encarecer la importancia del regadío, bien patente si se considera que, ocupando tal sólo el $15 \%$ de superficie cultivada, proporciona en torno al $60 \%$ de la producción final agraria (unos dos billones de pesetas) y absorbe el $30 \%$ de los jornales estimados en el sector, lo que representa unos 600.000 empleos teóricos. Estas cifras no deben ocultar, sin embargo, que los regadíos españoles son heterogéneos y sumamente dispares, cualquiera que sea el criterio clasificatorio adoptado.

Así, a tenor de las orientaciones productivas, el Avance del Plan Nacional de Regadíos (DIRECCIÓN GENERAL DE PLANIFICACIÓN RURAL Y DEL MEDIO NATURAL, 1995 a) diferencia catorce tipos: fruticultura subtropical (costas de Granada, Málaga y Canarias); horticultura precoz (litorales de Alicante, Murcia, Andalucía y Canarias); horticultura mediterránea intensiva (franja costera mediterránea); fruticultura mediterránea (Valencia, Murcia, Cataluña, Aragón); 
horticultura de valles interiores (interior peninsular); horticultura de las Mesetas (Castilla y León, Castilla-La Mancha); huertos familiares (todo el territorio); prados y áreas de montaña (Castilla y León, áreas de montaña de la mitad septentrional); extensivo cerealista y forrajero (interior peninsular); extensivos industriales (Andalucía, Castilla y León); intensivos industriales (Extremadura y Andalucía, primordialmente); vid, olivo y frutos secos (Andalucía, Castilla-La Mancha, Cataluña, Valencia, Murcia); arrozales (Marismas del Guadalquivir, Ribera del Júcar y Albufera, Delta del Ebro, principalmente), y arbóreos maderables (Castilla-León); gama toda ésta significativa, aunque claramente susceptible de matización. Contrastes muy notorios los hay asimismo de antigüedad, disponibilidades hídricas, procedencia del agua, métodos de riego, tipos de explotaciones predominantes, parcelarios, implicaciones ambientales, función social, rentabilidad, competitividad y perspectivas de futuro. Así, pues, aun ciñéndonos estrictamente al título de la ponencia, la riqueza temática es inagotable; de ahí que hayamos optado por centrar la atención en cinco aspectos que revisten, a nuestro juicio, especial relevancia: nuevos sistemas de riego, regadíos extensivos recientes, agricultura de vanguardia, sobreexplotación de acuíferos y modernización y expansión del regadío. En torno a dichas cuestiones bullen otras muchas, como, por ejemplo, los valores añadidos que obtiene el agua en los distintos cultivos.

\section{NUEVOS SISTEMAS DE RIEGO: VENTAJAS E INCONVENIENTES}

El Instituto de Reforma y Desarrollo Agrarios ha redactado, cara al "Plan Nacional sobre medidas aplicables para el Ahorro y la Reutilización de aguas en sus diversos usos" que debe acompañar al Proyecto del Plan Hidrológico Nacional según acuerdo adoptado por el Pleno del Congreso de los Diputados el 22 de marzo de 1994, y como instrumento puente de actuación, un borrador de "Plan Nacional de Modemización de Regadios, Horizonte 2000", donde, entre otros extremos, se señala que "la modernización de regadíos es un concepto muy amplio que va desde...el riego por goteo automatizado, bajo plástico, hidropónicos, fertirrigación informatizada, hasta la simple instalación de balsas de regulación que bien ubicadas permiten ahorros significatioos en el sistema" (INSTITUTO DE REFORMA Y DESARROLLO AGRARIO, 1995). El propio documento, haciéndose eco de datos habitualmente manejados, de compleja y difícil verificación, afirma que el regadío "representa en España el $80 \%$ de la demanda de agua y el $90 \%$ del consumo real (dado que otras demandas de agua no son consuntioas), y de una buena gestión de esta demanda dependen tres elementos básicos: ahorro de agua, mejora medioambiental y la viabilidad de una buena parte de la agricultura y agroindustrias españolas". 
Unos porcentajes de tal magnitud eximen de insistir en la singular importancia de este uso, pero, en cambio, hacen obligada la referencia a los distintos sistemas de riego y a volúmenes de agua requeridos por los mismos. El censo agrario de 1989 proporciona sobre métodos de riego los datos contenidos en el CUADRO 1:

\section{CUADRO 1}

Extensión de los regadíos según el método de riego empleado

\begin{tabular}{lrr} 
& Hectáreas & $\%$ \\
\hline Superficie regada por gravedad & 1.626 .041 & 64,6 \\
Superficie regada por aspersión & 620.880 & 24,7 \\
Superficie regada con riego localizado & 231.667 & 9,2 \\
Superficie regada con otros métodos & 39.272 & $\mathbf{1 , 5}$ \\
\hline
\end{tabular}

La superficie regada por gravedad lo es, sobre todo, mediante el sistema denominado "a manta" $\mathrm{y}$, con carácter complementario, por el llamdo "de surcos". El procedimiento tradicional, todavía ampliamente dominante, con profundo arraigo y alto grado de permanencia en las huertas históricas, es el riego por inundación o " $a$ manta"; se trata de la práctica despilfarradora por excelencia, inadmisible hoy desde una perspectiva estricta de economía del agua, aunque su pervivencia se halla favorecida, en unos casos, por generosas concesiones de aguas fluyentes, referibles las más antiguas a los repartimientos de la conquista cristiana, y, con carácter más general, por unas estructuras agrarias en las que privan minifundismo y pulverización parcelaria. El consumo unitario máximo corresponde al arrozal, con módulos del orden de $15.000 \mathrm{~m}^{3} /$ hectárea/cosecha, sin que baje de $10.000 \mathrm{~m}^{3} /$ ha/año el riego por inundación de otros cultivos, salvo que se restrinja mucho el número de riegos, como ha sido habitual en los regadíos deficitarios; en cualquier caso, el volumen requerido por esta práctica resulta, con planteamientos actuales, a todas luces, excesivo.

Por supuesto, el caso del arroz es diferente al de otros cultivos, en la medida que el riego por inundación resulta una exigencia ecológica; así, pues, el dilema se plantea en otros términos, es decir, mantenimiento o transformación del arrozal. A favor de la primera opción cuentan decididamente sus favorables perspectivas de mercado en la Unión Europea, potenciadas por el proceso altamente positivo de concentración y modernización que ha experimentado, en los últimos tres lustros, la industria arrocera española. Baste señalar que "Arrocerías Herba, S.A.", con su principal y gigantesca instalación en San Juan de Aznalfarache (Sevilla), son, con diferencia, las mayores de 
Europa, elaboran en torno al $90 \%$ de las cosechas andaluza y extremeña, cuentan con grandes superficies de arrozal y han propiciado el cultivo del arroz largo en las Marismas del Guadalquivir y regadíos del Plan Badajoz.

No es, empero, el arroz un cultivo exento de dificultades, que van desde la intensa fragmentación parcelaria de la marjal de la Ribera del Júcar y Albufera, a serios problemas de contaminación ambiental, para las tres zonas húmedas del litoral español consideradas en el Programa M.A.R. de excepcional interés y catalogadas en la categoría "A", es decir, Marismas del Guadalquivir, Delta del Ebro y Albufera de Valencia; al tiempo que resulta particularmente vulnerable en casos de sequía intensa, que, tal y como ha sucedido en la pasada campaña de 1995 en las Marismas, puede impedir la siembra, que también tropezó con serias incertidumbres, hasta última hora, en el ámbito valenciano.

Intimamente relacionado con el procedimiento anterior se halla el riego de surcos, con larga tradición en cultivos hortícolas y en plantíos nuevos de árboles, antaño frecuentemente asociados. El derroche no resulta tan clamoroso como en el primer caso, si bien las exigencias, variables de unas especies a otras, se sitúan entre 7.000 y $9.000 \mathrm{~m}^{3} / \mathrm{ha} / \mathrm{año}$. Se trata, no obstante, al igual que sucede en mayor medida con la anterior, de una modalidad incompatible con la racionalización y reducción deseables del consumo unitario.

En contraste con los susodichos procedimientos, otros, incorporados en este último tercio de siglo, permiten ahorros significativos o, incluso, de suma importancia; se trata del riego por aspersión y la microirrigación. El primero implica, con algunas otras ventajas complementarias, economías para cereal, viñedo y horticultura en las Mesetas, cultivos a los que se aplica preferentemente esta técnica, que oscilan entre 2.000-3.000 $\mathrm{m}^{3} /$ ha/año; su implantación mayoritaria radica en la gran y mediana propiedad, ofreciendo La Mancha ejemplo prototípico.

Una tecnología más avanzada, a veces con riguroso control informático a partir de sensores, representan las diversas modalidades de riego localizado, consistentes en microaspersión, exudación y, sobre todo, riego por goteo, procedimiento este último que ha conocido en los últimos años, y, particularmente desde los ochenta una gran difusión, hasta sobrepasar hoy las 350.000 hectáreas.

Han transcurrido más de cuatro lustros desde que comenzaron los primeros ensayos del riego localizado en el litoral del sureste ibérico, mediante goteros y accesorios de procedencia israelí. Como el material importado resultaba caro y las expectativas de venta excelentes, al tiempo que los prototipos no parecían excesivamente complejos, pronto menudearon modelos de fabricación española. Una cruda y gravosa experiencia demostró, acto seguido, que una instalación de riego por 
goteo no era tan simple como aparentaba. Cosecheros-exportadores y sociedades agrarias de vanguardia, pioneros en dicho empeño, padecieron lo que ellos mismos no dudan en calificar de "auténtico calvario"; centenares de miles de goteros desechados dan testimonio fehaciente de estas dificultades iniciales, que no consiguieron, empero, desalentar a fabricantes ni usuarios. Surgieron modelos de mejor acabado, mejoraron las instalaciones y su manejo, y, como resultado de todo ello, este procedimiento de riego localizado se ha difundido en los últimos quince años con inusitada rapidez, desbordando el ámbito hortofrutícola, para, acompañar, por ejemplo, nuevas plantaciones de olivo y también viñedos.

Las Comunidades Autónomas y la Administración Estatal pretenden incentivar ahora la expansión del riego por goteo como uno de los pilares básicos de la esbozada modernización de regadíos. En efecto, el riego por goteo implica economía y racionalización del consumo de agua, mejor aprovechamiento de fertilizantes, reducción de mano de obra y, en general, de costes, mayor cosecha y de mejor calidad, asî como transformación menos gravosa en terrenos de pronunciados declives.

La optimización del consumo de agua resulta, sobre todo, de la dosificación y oportunidad del riego, percolación reducida y evapotranspiración disminuida por el escaso desarrollo de hierbas y la exigua evaporación superficial; en los cultivos de invernadero o bajo cobertizo de plástico influye también mucho un microclima más húmedo; ventaja adicional para algunas cosecha (tomate, melón, alcahofa, entre ellas) es la posibilidad de emplear aguas ligeramente salinas, que benefician la calidad del fruto. El ahorro de agua varía según casos, del veinticinco al cincuenta por ciento, de manera que los consumos pueden reducirse a volúmenes de 3.000-5.500 $\mathrm{m}^{3} /$ ha/año, según cultivos. Subrayemos, sin embargo, que el norte habitual de la instalación del riego por goteo no es el ahorro de agua, sino el incremento de la rentabilidad.

Con todo, para una adecuada comprensión de la presencia creciente del riego por goteo en regadíos no deficitarios y hasta sobredotados, debe tenerse en cuenta que si la justificación primera de dicha técnica, que constituye un nuevo sistema de producción agrícola, es la de economizar agua, la reducción básica de costes en el precio final de la producción no se opera con dicho motivo, sino por el ahorro de mano de obra que resulta de la automatización de determinadas tareas (fertigación y herbigación), inferior dificultad de algunas, gracias al suelo seco entre hileras, y supresión de otras (en especial, tareas de abancalamiento y nivelado). Se ha comprobado asimismo un considerable aumento de cosecha al desarrollarse las plantas en condiciones más próximas a su óptimo ecológico, con relación hídrica muy favorable en el sistema radicular, mejor respiración, follaje seco y evitación de la perjudicial alternancia de embarrado y solidificación del suelo (RAMON MORTE, 1994). Hay, además, mediante fertigación, un aporte de nutrientes localizado y acorde con las exigencias de 
las plantas, y pérdidas por deslavado prácticamente despreciables. Todo ello repercute también en una mayor calidad del fruto (tomate, melón, sandía, pepino), es decir, en su sabor, color y consistencia, dato éste de gran importancia para el transporte. Otro aspecto de gran interés en terrenos de topografía desigual consiste en que las transformaciones, particularmente de superficies dedicadas a cítricos y frutales, pueden prescindir de costosísimos abancalamientos y limitarse a la mera suavización del relieve; exponentes muy notorios de este tipo de actuaciones hay en el Bajo Segura y en la depresión prelitoral del norte de Castellón y tampoco faltan en otras comarcas del litoral mediterràneo.

De la mano de cosecheros-exportadores, inicialmente, el riego por goteo mostró marcada preferencia por áreas de nueva transformación, no sometidas a la excesiva fragmentación de los regadíos tradicionales, pero ya, aunque en menor medida, tampoco está ausente de éstos y, como se ha dicho, es considerado como uno de los instrumentos primordiales de modernización de los mismos. Una acción pionera de esta naturaleza ha tenido por marco el regadío histórico de Mula (Murcia). La automatización y control de la red de riego localizado se consigue "gracias a la gran potencia informática de que la red hidráulica está dotada y la capacidad de los ordenadores en la Unidad Central, que reciben toda la información de la red y la procesan continuamente...... la programación incorporada al sistema tiene capacidad para gestionar el agua embalsada en función de la demanda en la red, optimizando su uso y distribución segín los criterios que sean establecidos".

La superficie con riego localizado censada en 1989 totalizaba 231.667 hectáreas, pertenecientes mayoritariamente al litoral mediterráneo, donde 132.162 hectáreas se repartían entre las Comunidades Autónomas de Murcia (38.135), Andalucía (36.499), Valenciana (28.629), Cataluña (26.167) y Baleares (2.734); de las restantes 99.505 hectáreas, algo más de la mitad correspondía a las provincias andaluzas de Huelva, Jaén y Sevilla, siguiendo en importancia, por este orden, las Comunidades de Canarias, Castilla-La Mancha y Aragón. Como se ha dicho, en la actualidad la cifra total puede exceder el $10 \%$ del regadío nacional, es decir, más de 350.000 hectáreas. En apoyo de esta estimación puede aducirse que, frente a las 28.629 hectáreas atribuidas a la Comunidad Valenciana en 1989, Ramón Morte, en 1992, verificó la existencia de 50.255 hectáreas, con la distribución provincial siguiente: Alicante, 32.995 (22.478 en el Bajo Segura); Valencia, 9.937; y Castellón, 7.323. Añadamos, en este mismo orden de cosas, que la expansión del riego por goteo en la Región de Murcia, donde cubre ya en torno al $40 \%$ del regadío, supera, en cifras relativas y absolutas, a la de la Comunidad Valenciana.

De los datos anteriores se desprenden una serie de conclusiones. En primer lugar, la fuerte concentración del riego por goteo en la franja costera del sureste ibérico, área pionera en su instalación y donde constituye piedra angular de la agricultura de 
vanguardia, centrada primordialmente en la producción hortícola. Significación bien distinta tiene la llamativa presencia de la provincia de Jaén, donde el riego por goteo, merced a su ductilidad, coloniza las "lomas rayadas de olivar", con espectacular avance estos últimos años tanto en plantaciones antiguas como recientes, a favor de la fuerte revalorización del aceite, producto que, lamentablemente controlada en gran parte su manipulación, envasado y venta por multinacionales francesas e italianas, cuenta con favorables expectativas de mercado exterior. A diferencia, la difusión de este método de riego en Huelva se debe, sobre todo, al auge adquirido por el fresón, convertido en auténtico cultivo emblemático de la llanura costera onubense.

Todo parece coaligarse para una expansión acelerada del riego por goteo, que contará con subvenciones estatales y autonómicas por su conceptuación como instrumento básico del ahorro de agua, encuadrado en diversas actuaciones para modernización de los regadíos. Por desgracia, no parece, sin embargo, que, particularmente en determinadas circunstancias, este procedimiento sea inocuo; menudean ya las llamadas de atención de los edafólogos sobre los problemas de salinización que el aporte localizado de abonos y la escasa percolación pueden acarrear al suelo.

\section{REGADÍOS EXTENSIVOS RECIENTES}

Las cinco comunidades con mayor número de hectáreas en regadío son Andalucía (703.777), Castilla y León (418.812), Aragón (402.822), Valencia (367.426) y CastillaLa Mancha (338.120); con la salvedad de la Comunidad Valenciana, en las cuatro restantes el regadío extensivo es ampliamente dominante.

Andalucía posee el regadío no sólo más extenso sino más variado de España, ya que incluye desde la fruticultura subtropical y la horticultura precoz al cultivo extensivo cerealista y forrajero, además de la horticultura mediterránea intensiva, el monocultivo del fresón en los arenales costeros onubenses, fruticultura mediterránea, áreas de cultivos industriales extensivos e intensivos, arrozales, viñedos y olivares. Entre 1904 y 1993 el regadío andaluz se ha triplicado con creces, registrando incrementos muy elevados, a excepción de Granada, en todas las provincias, particularmente en Sevilla, Córdoba y Jaén, con ascensos porcentuales respectivos, hasta 1987 , de $4.385,1.078$ y $232 \%$ (CANO GARCÍA, 1993).

En gran medida, estos nuevos regadíos del valle del Guadalquivir (casi 350.000 ha) se han orientado hacia cultivos extensivos mecanizables (maíz, remolacha azucarera, girasol y cultivos tradicionales de secano), en explotaciones de considerable extensión y con reducido empleo de mano de obra. Los resultados socioeconómicos de la transformación de extensas zonas (Plan Jaén, regadíos de 
Córdoba, margen derecha del Guadalquivir en tierras sevillanas y Bajo Guadalquivir) distan mucho de ser brillantes y ejemplares, particularmente tras la adhesión de España a la Unión Europea, la reforma de la PAC y el reciente acuerdo del GATT, si bien el grado de rentabilidad de los diversos cultivos en estos nuevos regadíos es muy diverso.

Molinero Hernando subraya que, a favor de los Planes de Desarrollo, el regadío conoció en el ámbito de la actual Comunidad Autónoma de Castilla y León una fuerte expansión, pasando de 194.700 hectáreas en 1960 a 361.900 en 1975 (MOLINERO HERNANDO, 1993). Y hace notar asimismo que los regadíos de la Tierra de Campos, es decir, la Zona Regable del Sistema Carrión-Pisuerga, se dedicaron básicamente, en un primer momento, al cereal, aunque después adquirieron más importancia otros cultivos como la alfalfa y el girasol. Se trata, en suma, de regadíos poco flexibles por el rigor y larga duración del invierno; ello no obsta para que, pendientes de desarrollo, se hallen calificados como de interés general de la Nación los planes de riego de Riaño (León) y Margen Izquierda del Tera (Zamora). No parece que sea ésta la vía de solución. Al contrario de lo que sucede en Aragón, el problema fundamental de las llanuras sedimentarias de Castilla y León radica en una sobreabundancia de mano de obra; para atenuar esta presión sobre la tierra, con un mercado excedentario y precios agrarios a la baja, podrían actuar, de consuno, ayudas al abandono de tierra, jubilación anticipada y política de rentas. Molinero Hernando prevé que aquí el desarrollo rural sostenible pasa por explotaciones familiares grandes, capitalizadas y bien gestionadas, proceso que, a tenor de los datos de la Encuesta sobre la Estructura de las Explotaciones Agrarias de 1987, habría comenzado a fraguar.

Aunque inconcluso, el Plan Bardenas-Alto Aragón ha repercutido poderosamente en la ampliación del regadío aragonés, que excede hoy ligeramente las 400.000 ha, cifra que casi duplicaría de saldarse la deuda histórica que representa, entre otros, el proyecto de Monegros II. Estas promesas por cumplir y otras cuestiones relacionadas con el esbozado macrotrasvase del Ebro, vital para el Plan Hidrológico Nacional, han sido plasmadas en el denominado "Pacto del Agua", aprobado y propuesto de manera unánime, en su día, al Gobierno de la Nación por todas las fuerzas políticas con representación en el parlamento regional, es decir, partidos Socialista, Popular, Aragonés Regionalista e Izquierda Unida.

Sin embargo, no es sólo problema de regulación de caudales y creación de infraestructuras para riego, determinados condicionamientos climáticos (esporádicas olas de frío, nieblas frecuentes, granizadas, vientos de largo recorrido) representan limitaciones que no pueden ser minimizadas. $Y$ no son las únicas, otras son fragmentación parcelaria, mano de obra escasa y cara, así como excesiva edad media de los titulares de las explotaciones agrícolas, circunstancia nada propicia a la innovación técnica. Por añadidura, los cultivos más difundidos (maíz, alfalfa) distan 
mucho de tener un futuro halagüeño. Ante todo ello, Frutos Mejías, señala que "parece obvia la necesidad de revisar la política de regadios llevada a cabo en las últimas décadas, $y$, sin renunciar a ella, considerar si las enormes inversiones de los grandes proyectos son realmente rentables para la comunidad y si no sería más racional promover, por una parte, la organización de pequeñas áreas regables, bien ubicadas en cuanto a condiciones ambientales, y, por otra, el asociacionismo, el cuidadoso estudio de las conexiones entre producción y mercado y la integración vertical entre dicha. producción y la agroindustria"(FRUTOS MEJÍAS, 1993).

Es de resaltar que la fase preparatoria del Anteproyecto del Plan Hidrológico Nacional ha dado ya ocasión para que se reaviven y actualicen viejos enfrentamientos por el disfrute del agua, con protagonismo creciente de las comunidades autónomas afectadas. Sirva de ejemplo prototípico la pugna entre agricultores manchegos y valencianos en torno al aprovechamiento del Júcar (GIL OLCINA, 1995). A pesar de la oposición de los segundos, temerosos de serios perjuicios en sus derechos inmemoriales sobre los caudales derivados secularmente para la Ribera y tierras aledañas, el regadío de la Mancha Oriental, dedicado primordialmente al cultivo del maíz, se ha más que quintuplicado en los últimos veinticinco años, superando actualmente las 75.000 hectáreas, con extracción masiva de aguas subterráneas. Entre los episodios más tensos y agrios del referido conflicto destaca la promulgación del Real Decreto $950 / 1989$, de 28 de julio, que declaraba de interés nacional la transformación en regadío de 69.000 hectáreas, con aguas del Júcar en Castila-La Mancha. Un paso más en la escalada de esta pugna supuso la sugerencia formulada por la Junta de CastillaLa Mancha, con motivo de la redacción del expresado Anteproyecto, de que la Administración Central procediese a la expropiación del hiperembalse de Alarcón.

La situación no es mejor en el sector manchego de la cuenca del Guadiana, donde un bombeo desmedido ha puesto en peligro de extinción el Parque Nacional de las Tablas de Daimiel, para atender la demanda de agua de unas $\mathbf{1 1 5 . 0 0 0}$ hectáreas, en su mayor parte de nuevos regadíos, donde privan cultivos de maíz y girasol. La grave situación planteada ha requerido una serie de actuaciones a las que luego aludiremos brevemente; entre ellas, la declaración de sobreexplotado, por parte de la Confederación Hidrográfica del Guadiana, para el denominado "Acuífero 23" de dicha cuenca.

\section{AGRICULTURA DE VANGUARDiA: UNA ACTIVIDAD MARCADA POR CONDICIONANTES FÍSICOS FAVORABLES Y FUERTE DEPENDENCIA EXTERIOR}

Sin infravalorar, y menos desconocer otras, no hay duda de que el área española donde la agricultura de vanguardia posee más entidad es la región climática del 
sureste ibérico (MARTíN GALINDO, 1988). Durante la segunda mitad del siglo actual, y particularmente en este último cuarto, las nuevas tecnologías han permitido no sólo superar las desventajas del clima y sacar el máximo provecho de sus posibilidades, sino beneficiarse de la más grave de aquéllas, aunque ésta, que conlleva la indigencia de recursos hídricos propios, no deje de suponer una sombría amenaza, cuya resolución reclama la transferencia de aguas foráneas. No es preciso encarecer que la dificultad que han padecido siempre los cultivos tradicionales ha consistido en la escasez, irregularidad y torrencialidad de las precipitaciones. A diferencia, hoy quienes practican nuevos sistemas de producción agrícola, bajo plástico o al aire libre, con riego localizado de alta frecuencia, ansían el agua, conducida desde distancias considerables, pero no la lluvia in situ, que mancha el fruto, propicia plagas u origina daños en los invernaderos; así, desde esta perspectiva, la rareza de la misma acaba por constituir una ventaja para esta nueva agricultura.

Es de notar, asimismo, que el enorme potencial energético, reflejado en luminosidad y temperatura, fundamento de las nuevas cosechas, que proporcionan tres mil horas de sol anuales, había contado más como rémora que condición favorable para una cerealicultura sumamente aleatoria $y$, casi siempre, de parvos rendimientos.

A pesar de esta llamativa mutación de inconvenientes en ventajas, el déficit de agua no ha hecho sino intensificarse en los últimos años; para enjugarlo o, al menos, paliarlo, se recurrió a la extracción desmedida y excesiva de recursos hipogeos, con situaciones rayanas o plenamente incursas en la sobreexplotación de acuíferos, cuya secuela más dañina es, como se ha indicado, la salinización.

Así, aridez, salinidad, microirrigación y agricultura de vanguardia se dan hoy cita en la región climática del sureste ibérico. Los nuevos procedimientos de riego, concretados primordialmente en el de goteo, constituyen piedra angular de los sistemas recientes de producción agrícola, que sitúan entre las áreas de mayor renta agraria (Almería es, por este concepto, la segunda provincia española) algunas que, secularmente, figuraron entre las más desheredadas. Los citados métodos de cultivo han repercutido ampliamente en la economía, paisaje y poblamiento de la franja costera del sureste ibérico; buena prueba de ello son los nuevos municipios de Pilar de la Horadada y, sobre todo, el Ejido, segregados de los términos de Orihuela y Dalías respectivamente, datos a los que se suma el llamativo engrandecimiento de otras pequeñas entidades, como, por ejemplo, Campohermoso en Níjar. Como caso prototípico, es de resaltar que El Ejido ha pasado de 2.641 habitantes, en 1960, a 41.374 en 1991.

La aseveración de que la franja litoral del sureste ibérico encierra la agricultura de vanguardia española pecaría obviamente de inexacta, al desconocer o infravalorar notorias e importantes manifestaciones de la misma en el resto de la costa. 
mediterránea, vertiente atlántica meridional y archipiélago canario, con diversas especializaciones y peculiaridades. Cabe, en cambio, afirmar, sin resevas, que nada resulta equiparable, por entidad y transcendencia, a la sorprendente mutación que en este último tercio de siglo ha experimentado la marina almeriense, singularmente la banda que, entre $36^{\circ} 41^{\prime}$ y $36^{\circ} 47^{\prime} \mathrm{N}$, con anchura media de diez kilómetros, se alarga treinta, teniendo por límites el Mediterráneo y, al norte, la Sierra de Gádor.

Una auténtica revolución agrícola, amplificada por la manipulación, transporte y comercialización directa de las cosechas, ha sido el gran revulsivo de la estancada y deprimida economía provincial; ha cortado la sangría emigratoria y permitido, como factor esencial, que la renta familiar disponible, tan sólo el $60 \%$ de la media nacional en 1967, haya igualado ésta en la actualidad (NAREDO PÉREZ ET AL., 1993). Unas pocas cifras sintetizan el significado de esta agricultura de vanguardia; baste decir que los cultivos hortícolas y de primicia, que ocupan 38.000 hectáreas (14\% de la superficie labrada), de ellas 24.000 bajo plástico, proporcionan casi el $90 \%$, en valor, de la producción final del subsector agrícola, cuyo monto, en 1992, excedió de 82.000 millones de pesetas (hortalizas, 80.653; flores, 2.000).

El medio físico del ámbito considerado ofrece, a un tiempo, serios inconvenientes y singularidades posibilidades a la actividad agrícola; la explotación de éstas y la superación de aquéllos se han conjugado en un proceso reciente, muy condicionado por factores técnicos y económicos. Condicionamientos negativos para el laboreo tradicional han sido: precipitaciones exiguas, muy irregulares y de elevada concentración horaria; cursos de agua reducidos a valles secos y, en el mejor de los casos, a ríos-rambla; suelos de escasa o pésima calidad y vientos de alto recorrido.

Fundamento de la agricultura actual son 3.000 horas de sol anuales, que suponen una fracción de insolación cercana al $70 \%$, con la subsiguiente luminosidad, inviernos muy suaves (enero, $12-13^{\circ} \mathrm{C}$ ) y casi inexistencia, dada su rareza, de heladas. Ya hemos indicado como los inconvenientes de antaño son hoy ventajas, por más que la insuficiencia de disponibilidades hídricas continúe siendo un factor limitante de primer orden. La clave de la tecnología que ha operado este cambio radical radica en el control de las dificultades físicas mediante riego, enarenado y cobertizos de plástico, de manera que este aprovechamiento del suelo ha sido certeramente descrito como "una agricultura de regadio desarrollada sobre suelo enarenado en invernaderos de plástico sin calefacción" (NAREDO PÉREZ ET AL., 1993).

Es de resaltar que en esta agricultura intensiva de alto valor los sistemas de riego (5.500 $\mathrm{m}^{3} / \mathrm{ha} /$ año en el Campo de Dalías) son muy eficientes, debido a la generalización del riego por goteo, microclima creado por los cobertizos de plástico, técnica del enarenado, redes de transporte y distribución entubadas, y, por último, balsas de regulación. 
La combinación de estos elementos, armonizados por una adecuada policía y gestión del agua, alcanza cotas modélicas en determinados sectores, como es, señaladamente, el caso de las 2.000 hectáreas del Sector VI del Campo de Dalías integradas en la "Commidad de Regantes Sol Poniente". Reducido en el Campo de Dalías el consumo de agua por ha/año de $7.000 \mathrm{~m}^{3}$ a $\operatorname{los} 5.500 \mathrm{~m}^{3}$ de la actualidad, se espera disminuir sensiblemente este último volumen con más información sobre el óptimo ecológico de cada cultivo y el perfeccionamiento de los sistemas de riego (NAREDO PÉREZ ET AL., 1993).

La rúbrica de horticultura precoz engloba en el sureste peninsular áreas bien diferenciadas por su orientación productiva, procedencia y calidad de los recursos hídricos, sistemas de cultivo, cuantía de las inversiones por unidad de superficie, parcelarios, tipos de explotaciones, regímenes de tenencia de la tierra, grado de asociacionismo y modo de comercialización. Así, por ejemplo, mientras el tomate de invierno, hasta la reciente expansión de la lechuga "iceberg", ha sido prácticamente un monocultivo en el tramo costero Mazarrón-Lorca-Aguilas (GIL OLCINA, 1989), al igual que la producción de sandía reviste especial interés en el Campo de Níjar (PORCEL y LARA, 1988), privan las explotaciones familiares dedicadas al cultivo de pimiento bajo cobertizos de plástico en el Campo de Cartagena, si bien en ninguno de los sectores mencionados dicho tipo de protección alcanza una continuidad comparable a la del Campo de Dalías, que, al aproximarse, procura la ilusión óptica de un auténtico "mar de plástico", con un inmovilizado medio (unas 2.000 pesetas $/ \mathrm{m}^{2}$ ) también netamente superior.

Hagamos notar asimismo que la agricultura de vanguardia, que tampoco se agota en los cultivos forzados e incluye, además de las hortícolas, producciones frutícolas, ha irradiado, en algunos casos, de la costa al interior, totalizando en 1994 unas 105.000 hectáreas, es decir, una tercera parte del regadío existente en el sureste ibérico (MORALES y RICO, 1996).

Quizá el ejemplo más notorio sea el de la lechuga "iceberg", que, merced a su ciclo corto y al elevado grado de tecnificación del cultivo, tras penetrar en la Depresión Prelitoral Murciana y desbordar luego la isohipsa de $500 \mathrm{~m}$., ha alcanzado el noroeste murciano y el altiplano de Jumilla-Yecla (MORALES GIL, 1995). En efecto, resulta ya muy considerable la superficie reservada a la "lechuga acogollada o iceberg", obtenida al aire libre, con labores y manipulación altamente automatizadas, que van desde la igualación del terreno con empleo de laser, siembra directa, con semilla empildorada, en las plantaciones más tempranas, o con cepellón, tras la fase de bandejas, en las tardías, fertigación, tratamientos sanitarios y arranque muy mecanizados, a la cadena de preparación y envasado, que concluye en un preenfriado al vacío para, según sean las condiciones del mercado, expedición o mantenimiento en 
cámara frigorífica. En verdad, el sistema de cultivo, y no digamos las operaciones ulteriores, semejan más un proceso industrial que una actividad agrícola.

Por vía asimismo de ejemplo, añadamos que en la propia Depresión Prelitoral Murciana (inmediaciones de Puerto Lumbreras), donde se beneficia de una elevada fracción de insolación, radica una explotación de claveles que, hoy en manos de capital japonés, cuenta con una significativa presencia en el mercado europeo de esta flor. Dotada de auténticos invernaderos con climatizadores automáticos, el inmovilizado alcanza $5.000 \mathrm{ptas} / \mathrm{m}^{2}$, con una repercusión del valor de la tierra en el mismo inferior al $10 \%$. Por supuesto, a la hora de cualquier cálculo de rentabilidad la referencia obligada es el coste de 50.000 .000 de pesetas a que sube la hectárea acondicionada.

Es preciso resaltar también el papel que en la creación de nuevos regadíos han desempeñado, sucesivamente, Grupos Sindicales de Colonización y Sociedades Agrarias de Transformación (SAT). El litoral mediterráneo, el atlántico meridional, los archipiélagos canario y balear y la cuenca del Guadiana, entre otras áreas, han conocido la actuación intensa de estas formas de asociacionismo agrario. Desarrollo del regadio, implantación de nuevos cultivos, difusión de innovaciones técnicas, manipulación y envasado de productos, guardan estrecha relación con dichas entidades. Actuaciones de esta naturaleza, con notable participación de las sociedades agrarias de transformación, han ocasionado en los espacios afectados mutaciones radicales del paisaje rural, de las estructuras agrarias y sistemas de cultivo, difusión de técnicas avanzadas e introducción de nuevas especies y variedades, así como sustancial cambio de las condiciones socioeconómicas y mejoras muy sustanciales de los niveles de vida.

Es de destacar que, en su gran mayoría, mediado el siglo actual, los espacios donde hoy arraiga la agricultura de vanguardia eran áreas de economía deprimida, aquejadas de procesos emigratorios crónicos, donde la relación entre la cuota de riqueza activa y el índice de población total arrojaba un grado de desarrollo sensiblemente inferior a la mitad del correspondiente al conjunto nacional. Esta desfavorable situación experimenta un cambio radical y mejora de forma muy ostensible a partir de los años sesenta, por diversas causas, entre las que descuellan la rápida expansión de una agricultura de alto valor comercial y el desarrollo turístico, que coexisten o entran abiertamente en conflicto.

En tramos cada vez más amplios del litoral mediterráneo peninsular y en los archipiélagos de Baleares y Canarias, el turismo compite ventajosamente con la agricultura, arrebatándole tierra y agua; a favor de una rentabilidad muy superior, el negocio turístico revaloriza el suelo, trocándolo en solar urbano, y minora la incidencia 
del coste del agua, derrochándola pródiga y despreocupadamente, exigiendo mayor disponibilidad.

Condicionantes climáticos, que implican cielos despejados, muchas horas de sol y precipitaciones escasas, propician la concurrencia de agricultura de vanguardia y afluencia turística, que se resuelve de formas diferentes, pero privando siempre el turismo, y haciéndolo de modo excluyente si precisa la totalidad de los susodichos recursos. Si el turismo no acapara el agua, coexiste, en mayor o menor grado, con una agricultura altamente tecnificada. En cambio, si aquél, como sucede en el sur de Tenerife, demanda, en alto porcentaje, el agua destinada a la agricultura, el retroceso de ésta, a despecho de que las transformaciones sean recientes y los métodos de cultivo innovadores, es fulminante (RODRÍlGUEZ BRITO, 1995, pp. 90-93). Asimismo, el sector agrícola ha retrocedido mucho y su importancia económica resulta incomparablemente inferior a la de los ingresos por turismo en la Costa del Sol occidental, con localidades de renombre internacional como Torremolinos, Fuengirola, Marbella y Estepona, donde el abastecimiento de agua, dada la fuerte asimetría estacional de la demanda turística y consumos individuales durante esa época del año que no bajan en dichos municipios de 500 1/día, ha de superar serias dificultades (MARCHENA GOMEZ, 1988). En cambio, la situación es distinta en otras áreas de la Andalucía mediterránea, señaladamente en la costa almeriense, donde una agricultura de vanguardia, con epicentro en El Ejido, ha hecho de esta provincia, como se ha indicado, la segunda, tras Valencia, en renta agraria de España. Segregado de Dalías, El Ejido es un verdadero núcleo hongo que ilustra de manera prototípica sobre la capacidad pobladora de la agricultura de vanguardia, desencadenadora de una corriente inmigratoria, en la que no falta la presencia legal o ilegal de extranjeros, en su gran mayoría magrebíes, que plantea cuestiones sumamente interesantes de competencia o complementariedad respecto de la mano de obra autóctona.

Subrayemos, por último, los puntos débiles de una actividad agrícola que conlleva serio riesgo económico, particularmente por los condicionamientos del mercado exterior, con precios muy volátiles. Baste recordar, por complejas que sean las motivaciones, las vicisitudes que desembocaron en la suspensión de pagos de "Pascual Hermanos, S.A.", que ha sido la compañía española más importante de exportación agrícola, o las multimillonarias pérdidas ocasionadas a BANESTO por su gran explotación agrícola de "Tierras de Almería". Infinidad son los quebrantos de eventuales y poco avezados empresarios agrícolas atraídos por el deslumbrante señuelo de una actividad en la que la fuerte incidencia del factor aleatoriedad ha de ser debidamente medida y compensada.

Dependencia permanente del exterior es la que se padece respecto de la investigación agronómica, particularmente acusada en la adquisición de semillas de variedades híbridas, pagadas, casi literalmente, a "precio de oro" (un kilogramo de 
semilla de tomate puede exceder ampliamente del millón de pesetas), a multinacionales holandesas, que controlan y monopolizan este mercado, cuya importancia y trascendencia no es preciso encarecer.

Aspecto digno de mención son los impactos ambientales desfavorables de la agricultura de vanguardia. Uno, bien perceptible, es de alcance paisajístico, al afear los cobertizos de plástico espacios costeros de gran belleza; y es preciso encarecer que sus consecuencias no se limitan al plano puramente estético, aun siendo éste por sí mismo tan valioso y digno de protección, sino que pueden condicionar negativamente el potencial turístico del área afectada. Pero añadamos, a continuación, que en el haber de la agricultura de vanguardia se contabilizan, en cambio, consecuencias altamente positivas, tales como mejora de nivel de vida, propagación de un dinamismo económico que trasciende el municipio y la comarca, generación directa e indirecta de empleo, inversión del proceso emigratorio y estabilización o fuerte incremento demográfico, y aportación sustancial de ingresos a la balanza comercial.

Ya se ha señalado reiteradamente el deterioro de aguas por la sobreexplotación de acuíferos y los daños que puede ocasionar al suelo el sistema de fertigación inherente al riego localizado, si aquél no es renovado o adecuadamente lavado. Problema por resolver es también la eliminación de materiales de desecho, que van desde los plásticos, por su carácter no biodegradable, de cobertizos, pequeños túneles y acolchados a la fibra de roca y otros soportes artificiales de los cultivos hidropónicos.

\section{SOBREEXPLOTACIÓN Y DETERIORO DE ACUÍFEROS}

El extraordinario incremento de la demanda de agua en esta segunda mitad de siglo ha sido originada, muy en primer término, por la espectacular expansión del regadío, causa acompañada, a distancia, por la multiplicación de los consumos urbano, industrial y turístico. Dicho proceso ha requerido, junto a la regulación creciente de los ríos, exhaustiva en algún caso, y los trasvases, una ingente extracción de aguas subterráneas para dichos usos, entre los que descuella poderosamente la actividad agrícola. Es de resaltar que, hasta mediados de la centuria actual, el regadío atendido con caudales subterráneos, aflorados mediante cimbres, presas subálveas, galerías de distinto tipo, pozos artesianos, norias de tracción animal, molinos de viento diversos y bombas centrífugas, era relativamente poco importante, situación que cambia por entero y aceleradamente desde entonces, merced a la rápida difusión de bombas de eje vertical y gran potencia, capaces de explotar freáticos a centenares de metros de profundidad. 
El Ministerio de Obras Públicas y Urbanismo declaraba, abierta y paladinamente, en 1985, que "no son muy completos los datos de que se dispone en España sobre la utilización de las aguas subterráneas". Afirmación sincera, cierta y preocupante; calificativo este último que, cuando menos, merece dicho grado de desconocimiento de una cuestión de vital importancia para algunas de las áreas con mayor productividad agrícola, índice de urbanización, progreso industrial y desarrollo turístico de España, así como para la preservación de determinadas zonas húmedas de singular interés ecológico. Transcurrido un decenio, los inventarios de los recursos de agua y de las estructuras de su gasto, al igual que los de superficies regadas, distan mucho de ser satisfactorios. Recientemente, los Proyectos de Directrices de Planes Hidrológicos que, elaborados por las distintas Confederaciones Hidrográficas, han prestado base a la confección del Anteproyecto del Plan Hidrológico Nacional, subrayan las limitaciones de los datos manejados, así como las insuficiencias de las redes de observación (CONFEDERACIÓN HIDROGRÁFICA DEL JÚCAR, 1992).

Como ejemplo prototípico y harto expresivo de la precaria información estadística sobre el tema de referencia, baste indicar el abultado desfase entre las cifras de regadío recogidas por el Censo Agrario de 1989 y las que, cuatro años después, figuran en la Memoria del Anteproyecto del Plan Hidrológico Nacional. Según la primera de estas fuentes, el regadío totalizaba 2.517 .833 hectáreas, de ellas, 750.913 , es decir, el 29,82\%, con aguas subterráneas; en cambio, para la segunda, la superficie bajo riego asciende a 3.196 .305 hectáreas, de las cuales 919.461 , o sea, el $28,76 \%$, con caudales hipogeos. Todo parece indicar que, aun con reservas, los últimos valores serían los más próximos a una realidad no conocida con la debida precisión y, desde luego, notoriamente variable de una campaña agrícola a otra. El desglose de la extensión del regadío que cuenta con recursos subterráneos figura en el CUADRO 2.

Por encima del porcentaje medio (29\%) de regadío con aguas subterráneas quedan, además de los archipiélagos de Baleares $(97 \%)$ y Canarias $(82 \%)$, las cuencas hidrográficas del Pirineo Oriental (65\%), Júcar $(57 \%)$, Guadiana (47\%) y Segura (47\%), orden que, con sólo una variante, coincide con el resultante de la relación entre los volúmenes de recursos hipogeos y superficiales de destino agrícola; no obstante, la comparación de unos y otros porcentajes resulta significativa. Así, en la segunda de las relaciones se produce el salto al primer puesto de las cuencas internas de Cataluña, donde las aguas subterráneas suponen el $94 \%$ de las consumidas para riego, aunque la superficie beneficiada por aquéllas es el $65 \%$ de la total y el consumo por ha/año sube a $8.477 \mathrm{~m}^{3}$; tras ello hay un marcado predominio del cultivo hortícola intensivo con notable predominio del riego por inundación (vid. CUADRO 2).

En el otro extremo aparece la cuenca del Segura, con porcentajes respectivos de 25 $\%$ y $46 \%$, y una modesta dotación por hectárea y año de $3.571 \mathrm{hm}^{3}$, resultante de una situación compleja, que, bajo el denominador común de un déficit hídrico agobiante, 


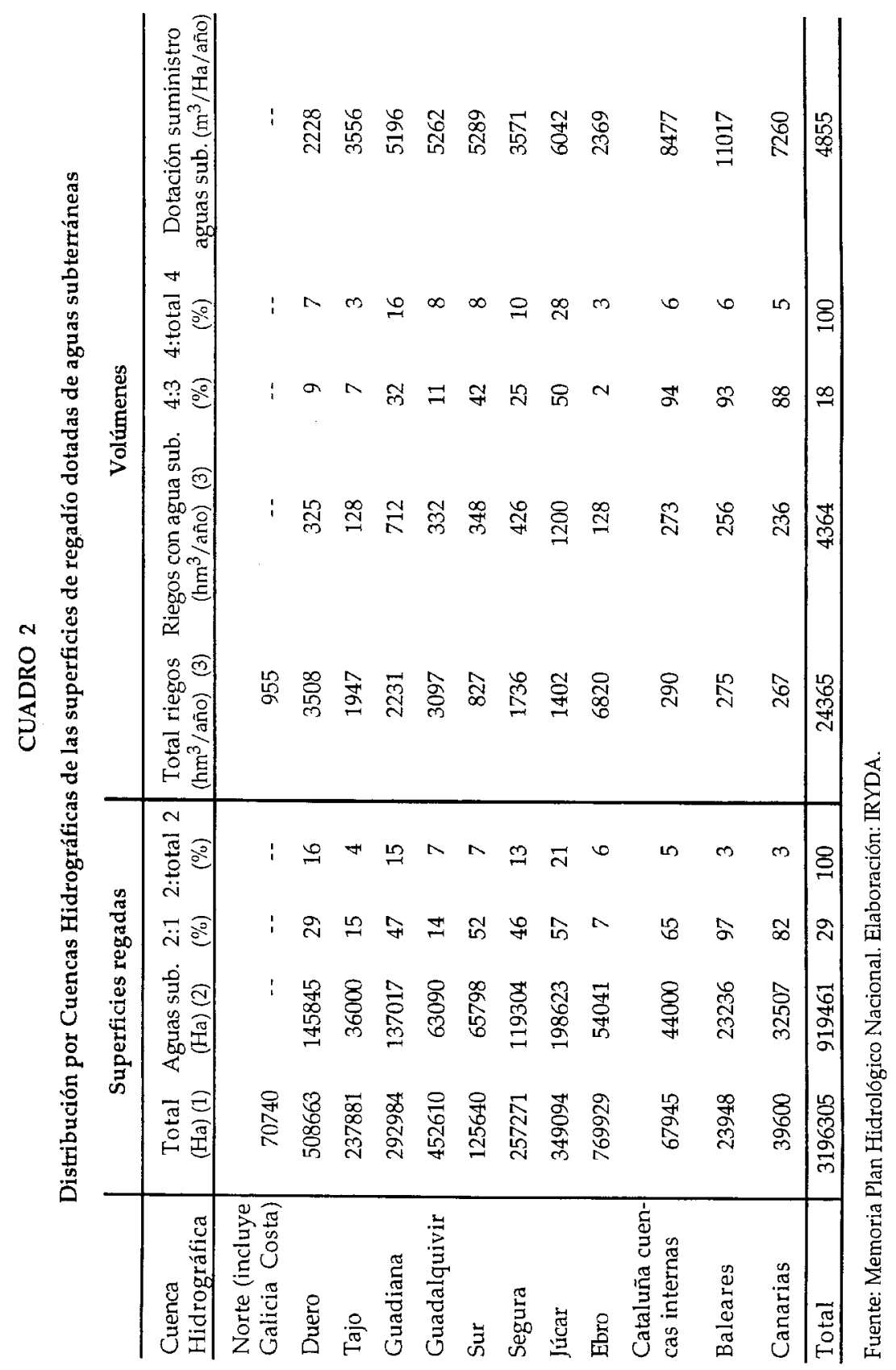


auna regadíos deficitarios y creciente difusión del riego por goteo en amplias áreas de los secanos transformados con pozos. Una posición intermedia es la de la cuenca del Guadiana, donde el consumo de $5.196 \mathrm{~m}^{3} / \mathrm{ha} /$ año es el de un regadío extensivo, con cereal de invierno, maíz y girasol, y notoria presencia del riego por aspersión. En la cuenca del Júcar se pone de manifiesto que los nuevos regadíos hacen, con mejores redes de distribución e incidencia muy superior del riego localizado, un menor consumo unitario de agua.

Nada de particular tiene que haya sido en estas áreas, donde con más o menos gravedad y amplitud, bombeos excesivos han acarreado problemas de sobreexplotación, con secuelas sumamente pejudiciales, la más grave de las cuales es la salinización. La escasez de estudios específicos y, por ello, una carencia de cifras concluyentes ha permitido, estos últimos años, al hilo de la elaboración y promulgación de la nueva Ley de Aguas de 2 de agosto de 1985, y ahora con motivo de la redacción del Anteproyecto del Plan Hidrológico Nacional, una viva polémica en torno a la sobreexplotación de acuíferos. LLAMAS MADURGA (1986) la calificó en 1985, de "mito y coartada para la nacionalización", arguyendo que los acuíferos sobreexplotados no representan una extensión superior al $1 \%$ del territorio español ni proporcionan un volumen superior al $10 \%$ de las aguas extraídas, por término medio, al cabo del año en el conjunto del mismo. Calvo García-Tornel hace notar que, aun admitidas las apreciaciones anteriores, no cabe desconocer que esas cifras, en apariencia modestas, representan en torno a medio millón de hectáreas, en su mayoría regadíos intensivos hortofrutícolas, y una extracción indebida de más de $500 \mathrm{hm}^{3}$ al año (CALVO GARCÍA-TORNEL, 1988, p. 147); con independencia, y esto es indudable, de que determinadas situaciones revisten extrema gravedad, tal y como sucede en ciertas áreas del litoral mediterráneo, particularmente de la costa valenciana y del sureste peninsular, cuanca del Guadiana y archipiélago canario.

Sirvan de muestra algunas conclusiones a las que llega RODRÍGUEZ ESTRELLA (1987) a partir del examen de los sistemas acuíferos de la región de Murcia, en el corazón del sureste ibérico; según ellas, "los recursos en aguas subterráneas de la Región

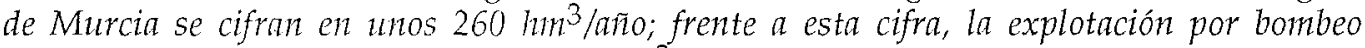

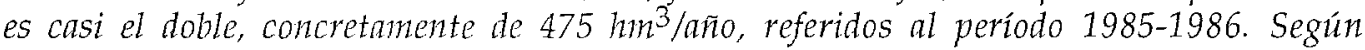
las cifras anteriores, en el conjunto de la región existe un estado casi generalizado de sobreexplotación de las zonas hidrogeológicas...la sobreexplotación ha traido consigo: un descenso de niveles (en Mazarrón-Aguilas, en ocasiones es de hasta 15 m/año; un aumento en la profundidad del agua (en Guadalentín y Ascoy-Sopalmo se superan ya los 200 metros); el abandono de muchas captaciones (en Jumilla-Villena de las casi 100 existentes sólo bombearon 52 en 1985); la aparición de gases (en Mazarrón-Aguilas y Guadalentin); y el empeoramiento de la calidad quimica (en D. Gonzalo-La Paca ha pasado en algunos sondeos en los cinco últimos años, de una salinidad inferior a $1 \mathrm{~g} / \mathrm{l}$ a tener más de $5 \mathrm{~g} / \mathrm{l})^{\prime \prime}$. Como se ve, las consecuencias de una extracción excesiva y 
desequilibrada son sumamente graves; para enfrentarlas, un Real Decreto de 30 de diciembre de 1986 dispuso que, hasta tanto no se aprobara por el gobierno el Plan Hidrológico de la Cuenca del Segura, quedasen reservados a favor del Estado los recursos potenciales de aguas subterráneas y epigeas en dicho ámbito, de manera que sólo podrán otorgarse concesiones de aguas subterráneas para sustitución de caudales ya, legalmente, establecidos.

Ejemplo prototípico de bombeo desmesurado constituye el sistema de JumillaVillena, que ha trocado la existencia de pozos artesianos en el primer cuarto del siglo actual por una declaración provisional, con fecha 31 de julio de 1987, de acuífero sobreexplotado, situación que también sufre el de la Sierra de Crevillente.

El sistema de la Sierra de Crevillente constituye uno de los ejemplos más espectaculares de acuífero sobreexplotado; cuarenta años atrás, en la Galería de los Suizos las aguas manaban caballeras, hoy las profundidades de extracción se aproximan a 600 metros y se precisan electrobombas sumergibles de $1.000 \mathrm{CV}$ de potencia, con costes desorbitados de alumbramiento $\left(80 \mathrm{ptas} / \mathrm{m}^{3}\right.$ en energía eléctrica), ritmos de descenso piezométrico superiores a $25 \mathrm{~m} /$ año y unas reservas, tras ser dilapidadas, prácticamente inexistentes. En 1989, los elevados contenidos en cloruros y sulfatos, muy por encima de los límites tolerables en aguas para abastecimiento público, obligaron a los ayuntamientos de Aspe y Hondón de las Nieves a solicitar una conexión de socorro a la Mancomunidad de los Canales del Taibilla. La situación actual de los regadíos no es menos dramática, pues al elevado precio del agua para riego se auna un desmesurado contenido en sales que ha motivado, en combinación con problemas de mercado y desastres meteorológicos, el abandono de más de 2.000 hectáreas de Uva de Mesa Embolsada del Vinalopó, única en el mundo con denominación de origen (RICO AMORÓS, 1994).

En esta segunda mitad de la centuria, la multiplicación de captaciones con potentes bombas de eje vertical y sumergibles no sólo ha hecho desaparecer el aprovechamiento de aguas caballeras y extinguido los pozos artesianos, sino que, además, ha producido un espectacular descenso de los niveles piezométricos y de salinización en el borde oriental del acuífero, hecho que ya se había hecho sentir, de forma preocupante, a comienzos de los años setenta en el cuaternario de Villena, determinando el abandono de la mayoría de sondeos del paraje del Zaricejo. Por entonces, MIRA CÁNOVAS (1976) señalaba que "las 256 labores inventariadas en el término municipal de Villena, ponen de manifiesto la importancia de sus aguas subterráneas, y su proliferación viene planteando desde la década de los cincuenta el peligro de sobrexplotación del área de captación, hasta tal punto que ya en el año 1959 se establece por Decreto un Perimetro de Protección tendente a la limitación de las obras de captación y extracciones en su entorno". 
Sin infravalorar otros muy serios, el efecto más grave que conlleva para la fachada este de España el bombeo excesivo de aguas subterráneas es la salinización; tal y como señala Custodio, "In mezcla con aguas saladas es una verdadera contaminación, y una de sus formas más insidiosas y frecuentes en las áreas costeras, ya que es capaz de degradar y aun inutilizar grandes volúmenes de agua y el acuifero. Basta un $2 \%$ de agua marina para producir una agua subterránea con serios reparos para su potabilidad y afectar a su calidad agricola o usos industriales. A inutilizarla para la mayoría de los usos basta con un 5 \%" (BURDALO y DELGADO, 1987).

Se trata de un riesgo generalizado, y con severas manifestaciones, en la franja litoral, sin que resulte exclusivo de la misma. Dicho proceso en los acuíferos costeros deriva de la intrusión marina, mientras en los del interior, como sucede con los sistemas de Sierra de Crevillente y Jumilla-Villena, resulta de la profundización de las captaciones y de su mayor densidad en campos de bombeo próximos al Keuper salífero. Obviamente, esta fuente de contaminación salina, sin perjuicio de que se halle extendida y amenace importantes freáticos continentales, carece de la omnipresencia que reviste el peligro de intrusión marina en la costa, con el agravante de que ésta opera de manera subrepticia, reemplazando el agua dulce por la salina sin acusado descenso de niveles piezométricos; el propio Custodio resalta que ".....si se puede admitir un tránsito brusco entre el agua dulce y el agua salada, la utilización y sustitución de 10 metros de agun dulce sólo supone un descenso de 0,25 metros en el nivel del agua, mientras que en un acuifero continental se observaria un abatimiento de 10 metros" (BURDALO y DELGADO, 1987). De ahí que, frecuentemente, cuando el deterioro se advierte, sea irreversible o de muy costosa corrección.

Fue la región climática más seca de España la primera en sufrir las consecuencias de la penetración de agua de mar, que inutilizó multitud de pozos abiertos en el tramo litoral murciano-almeriense comprendido entre los polos secos de Cabo Tiñoso y Cabo de Gata. Ha sido el deterioro de acuíferos en las regiones de Valencia y Andalucía el hecho que condujo a adquirir plena conciencia de la gravísima amenaza que constituye la intrusión marina.

El serio problema planteado en los llanos litorales valencianos con la salinización de acuíferos por intrusión marina, que tan grave y justificada preocupación despierta ahora, dista mucho, empero, de ser una novedad; ya en 1966 Llamas había anunciado el peligro y seis años después Moncófar padecía las consecuencias. Dicho término pertenece a la Plana de Castellón, que es, seguido por el Campo de Morvedre (Sagunto), el sistema valenciano con mayor grado de deterioro, si bien no son los únicos afectados. Ambos acuíferos forman parte de la unidad hidrogeológica Espadán-Sagunto, cubren una superficie aproximada de $400 \mathrm{~km}^{2}$ en el relleno detrítico de la llanura costera y su espesor máximo llega a 270 metros en la zona central. Según las estimaciones de RODRÍGUEZ ESTRELLA (1986), las entradas 
de los dos acuíferos suman, por término medio, $239 \mathrm{hm}^{3}$ anuales, de los cuales unos diez son de agua marina; por su parte, las salidas, que merman las reservas, llegan a 255 $\mathrm{hm}^{3} / \mathrm{año}$, de los cuales 201 se consumen en riego $\left(158 \mathrm{hm}^{3}\right)$ y abastecimientos urbanos e industriales. En consecuencia, se produce un déficit en torno a $16 \mathrm{hm}^{3}$, que no afecta por igual, ni mucho menos, a los referidos sistemas en toda su extensión: inexistente en determinados sectores, es, en cambio, localmente acusado coincidiendo con áreas de intensa extracción, en las que ha originado la aparición de conos piezométricos que, al quedar por debajo del nivel marino, invierten la dirección del flujo y dan entrada al agua marina, causante de la salinización del acuífero. Fenómenos de dicha naturaleza se han dejado sentir, con más o menos intensidad, en otros puntos del litoral valenciano como Vinaroz, Benicarló, Peñíscola, Torreblanca, Oropesa, Vergel, Denia y Jávea (RODRÍGUEZ ESTRELLA, 1986).

Las secuelas de la salinización ya se han hecho notar en plantaciones de cítricos y nísperos, ocasionando primero un decaimiento de los árboles, seguido de necrosis en el borde las hojas y disminución de cosecha, para llegar, en algún caso extremo, a la anulación de ésta y a la propia muerte del árbol; subrayemos como efectos aún más graves el progresivo deterioro de los acuíferos y la salinización del suelo, daños de muy difícil y, en todo caso, costosa corrección.

A comienzos de siglo las aguas hipogeas se extraían en los llanos costeros valencianos a menos de diez metros, profundidad que ahora se ha quintuplicado o decuplicado $y$, de continuar el descenso de niveles piezométricos al ritmo de los últimos cincuenta años, para finales de este siglo y milenio nos encontraríamos con perforaciones entre 150 y 250 metros, supuesto inviable ya que acarrearía una salinización generalizada al no hallarse la mayoría de pozos a más de diez kilómetros de la línea de costa. Para evitarlo es urgente restringir los bombeos; dicha reducción sería drástica en las tierras septentrionales de la provincia de Castellón y en la comarca de La Safor, donde se proyecta un completo ahorro agrícola de caudales subterráneos mediante transferencias del Ebro.

Tal y como se indica, los acuíferos de Tarragona, Castellón y Valencia sufren dificultades localizadas de sobreexplotación, que todavía pueden ser enfrentadas y resueltas mdiante una adecuada redistribución de recursos propios o próximos, con algunas salvedades. Por el contrario, en el sureste ibérico la insuficiencia muy aguda de agua ha llevado a la explotación de reservas fósiles, abocando a una situación que no parece tener otra escapatoria sino la derivada de un conjunto de actuaciones, concretadas primordialmente en la racionalización y optimización de consumos, reciclaje de residuales, aportaciones foráneas e instalación de potabilizadoras.

Es de notar que los alarmantes descensos de niveles freáticos en áreas costeras y prelitorales de las provincias de Almería (Pulpí, Huercal-Overa, Bajo Andarax y 
campos de Níjar y Dalías) y Huelva (zona occidental), rayanos o incursos en la sobreexplotación, con intrusión marina o riesgo inminente de ella, ha motivado la promulgación, al amparo del Art. 56 de la vigente Ley de Aguas, del Real Decreto de 24 de diciembre de 1986, instrumento para la entrada en vigor, con relación a dichos acuíferos, de las medidas previstas para los declarados provisionalmente sobreexplotados, como forma de obviar los trámites normales previstos en el Reglamento de Dominio Público Hidráulico.

Sobreexplotación relevante y con gran resonancia, por amenazar la propia existencia del Parque Nacional de las Tablas de Daimiel, es la que padece el célebre "Acuífero 23", en la Cuenca Alta del Guadiana. Tras los estudios efectuados por el Servicio Geológico del Ministerio de Obras Públicas, el Organismo de Cuenca ha declarado sobreexplotado dicho acuífero. Entre los datos más expresivos del referido informe figuran los siguientes: en 1984, las 101.268 hectáreas atendidas con aguas subterráneas en el área indicada precisaban $430 \mathrm{hm}^{3}$ anuales, con otros $28 \mathrm{hm}^{3}$ para abastecimiento urbano y consumo industrial, es decir, unas salidas para uso humano de $458 \mathrm{hm}^{3}$, frente a unas entradas de $340 \mathrm{hm}^{3}$, generándose así un déficit superior al centenar de hectómetros cúbicos, que ha comportado la práctica extinción de la descarga natural al Guadiana. Baste añadir, como noticia complementaria, que en el intervalo 1981-84 se transformaron en regadío 16.000 nuevas hectáreas, y, más aún, mientras la superficie regada aumentó un $19 \%$, las extracciones lo hicieron en el $23 \%$, de manera que el incremento de éstas no resulta sólo de la ampliación de aquélla, sino también del mayor gasto unitario, derivado de la propagación de cultivos (maíz, girasol) más exigentes en agua. Según López Camacho, que dirigió el mencionado estudio, la supervivencia de las Tablas de Daimiel requiere tres tipos de actuaciones conjuntas, consistentes en la reducción de los consumos de agua, máximo aprovechamiento de los recursos hídricos del Alto Guadiana y las transferencias de recursos foráneos (PARRONDO, 1987). Estas últimas ya se han producido, esporádicamente, a través del trasvase Tajo-Segura, y el Anteproyecto del Plan Hidrológico Nacional las garantiza; sin embargo, las Tablas de Daimiel y buena parte de la llanura manchega se convertirán en un pozo sin fondo si no se atemperan los bombeos, destinados mayoritariamente, por otra parte, a cultivos cuyo futuro no parece muy prometedor.

La recuperación de acuíferos y suelos salinizados es difícil y costosa, de ahí que se imponga la conveniencia de una política preventiva, enmarcada por un adecuado desarrollo normativo y correcta aplicación de la actual Ley de Aguas en su ámbito de vigencia; todo ello parece inseparable de investigaciones hidrogeológicas, climáticas y de escorrentía, control de bombeos, recarga de acuíferos, corrección de desequilibrio hídricos y optimización del consumo de agua, señaladamente con la sustitución, allí donde resulte oportuno, de los sistemas de riego tradicionales por la aspersión y la microirrigaciôn. 
Tras la intrusión marina, el mayor agente contaminante de los acuíferos son los abonos nitrogenados, proceso que reviste particular gravedad en los regadíos intensivos catalanes, valencianos, murcianos y andaluces, sin excluir determinadas áreas manchegas. En los freáticos afectados, los $50 \mathrm{mg} / \mathrm{l}$. de nitratos fijados como contenido máximo en el Código Alimentario Español son ampliamente rebasados, duplicándolos con frecuencia, cuadriplicándolos y alcanzando en casos puntuales los 300 miligramos por litro. En este sentido, ha de destacarse que el consumo de abonos nitrogenados ha registrado desde los años sesenta un crecimiento exponencial, con aporte excesivo de los mismos en muchas ocasiones, dañando seriamente los acuíferos. A la voz de alarma técnica ha respondido ya parte del sector agrícola; así, por ejemplo, la Asociación Valenciana de Agricultores (AVA) ofrece análisis gratuitos para determinar el contenido de nitratos, cloruros y pesticidas (atrazinas, diurón y bromacil); se pretende así preservar la calidad del agua y evitar dispendios costosos y perjudiciales de nutrientes y productos fitosanitarios.

\section{MODERNIZACIÓN Y EXPANSIÓN DEL REGADÍO}

Dos meses antes de las penúltimas elecciones generales, el mismo día que se aprobaba el Decreto de disolución de las Cortes, en abril de 1993, el Gobierno decidía también remitir al Consejo Nacional del Agua, a efectos del preceptivo informe, el Anteproyecto del Plan Hidrológico Nacional, que contenía, entre otras, la propuesta de incremento de la superficie regada en 600.000 hectáreas. Seguía su trámite en dicho órgano el referido Anteproyecto, al que se formularon 1.143 alegaciones, cuando el Pleno del Congreso de los Diputados, con motivo de una Interpelación Urgente del Grupo Parlamentario Popular, acordó, el 22 de marzo de 1994, instar al gobierno para que, entre otros documentos, remitiese "al Congreso de los Diputados, junto con el Plan Hidrológico Nacional, un Plan Agrario de regadios donde se contemple con precisión la superficie de nuevos regadios, la superficie de regadio actual a mejorar, el consumo $y$ ahorro de agua, cultivos a establecer en concordancia con la reforma de la PAC. y et acuerdo del GATT, los correspondientes estudios de rentabilidad y las posibles alternations a los mismos, asi como zonas a transformar en regadio por razones sociales". Unos días después, el Ministerio de Obras Públicas, Transportes y Medio Ambiente, ante el elevado número de observaciones y enmiendas planteadas, concluyó, con fecha 25 de marzo de 1994, el denominado Informe sobre las propuestas de modificación del Anteproyecto del Plan Hidrológico Nacional, que, tras su rectificación por la Permanente del Consejo Nacional del Agua, fue elevado al Pleno del mismo, que abrió plazo para el examen y presentación de observaciones; concretándose, finalmente, todo ello en el definitivo, por ahora, Informe sobre las propuestas de modificación del Anteproyecto del Plan Hidrológico Nacional de 20 de julio de 1994 (CONSEJO NACIONAL DEL AGUA, 1994). 
El objetivo originario de las 600.000 hectáreas de nuevos regadíos ha sido reemplazado en el susodicho Informe, con la evidente intención de revisarlo a la baja, por una banda de 600.000-400.00 ha, cifra esta última que, significativamente, casi coincide con la extensión global a transformar (428.592 ha) asumida por declaraciones que conceptúan como áreas de interés nacional o de interés general de la Nación los diversos espacios afectados.

Recientemente TIÓ SARALEGUI (1995) ha resaltado, con evidente razón, la complejidad que reviste la elaboración del Plan Nacional de Regadíos, "al entrelazarse eunluaciones técnicas, económicas y medionmbientales con aspiraciones sociales y regionales que no siempre pueden valorarse con el mismo sistema de unidades", subrayando que "la dinámica social y politica que ha llevado a considerar el regadio y el agua como la primera reivindicación histórica en gran parte del territorio español puede convertirse en el primer factor de estimulo a la irracionalidad en la toma de decisiones". Frente a ello, el citado autor, a la sazón Secretario General de Estructuras Agrarias, sostenía, con impecable argumentación, que "ni los nuevos regadios aseguran siempre el progreso social y el desarrollo económico, ni la agricultura intensiva es viable en todas las comarcas españolas de secano, ni la agriculturn tiene, por qué ser la única alternativa de desarrollo rural en aquellas zonas en que no se ha mostrado históricamente como competitiva".

Poco después, en octubre de 1995, el Aonnce del Plan Nacional de Regadios (Informe de sintesis), redactado por la Dirección General de Planificación Rural y del Medio Natural, subraya que "la politica de nuevos regadios queda condicionada por la existencia de un conjunto de compromisos históricos adquiridos en zonas declaradas en su día de Interés Nacional y de Interés General de la Nación que implica la puesta en riego de 428.592 hectáreas. De no procederse a la revisión de estas Zonas, la planificación de regadios futuros se agota en la realización de estas transformaciones, que podrian requerir un horizonte temporal minimo de 30 a 40 años, con el actual esfuerzo presupuestario en materia de regadios". Para añadir, a renglón seguido, que "la propuesta del M.A.P.A. es una revisión en profundidad, utilizando un conjunto de criterios técnicos, sociales, económicos y medionmbientales. Como consecuencia, en este avance se propone la realización selectiva de los Planes en curso, con unos objetivos en el horizonte 2005. El resto de las zonas declaradas deberá someterse en el marco del P.N. de Regadíos, junto a cualquier otro regadio potencial o propuesto por CC.AA. o Cuencas Hidrográficas, a una minuciosa evaluación que permita fijar una escala de viabilidad y prioridades".

La primera de las conclusiones que, a modo de decálogo, cierran el expresado Avance, resalta que el objetivo prioritario del Plan Nacional de Regadíos es la mejora, modernización y consolidación del regadío actual, como base del complejo agroalimentario, matizando que "la dinámica de los mercados y las limitaciones 
climatológicas que pueden llegar a acentuarse en el futuro (sic) obligan a considerar la reestructuración y reconversión de alguna de las zonas tradicionales de riego, mediante estudios singulares caso a caso, al tiempo que aconsejan considerar las demandas potenciales en expansión de cultivos tradicionalmente de secano (olivar y viñedo) que ocupan un lugar clave del complejo agroalimentario más competitivo a nivel internacional".

Así, pues, como referencias básicas del Plan Nacional de Regadíos figuran la mejora de los existentes y, con carácter complementario, nuevas transformaciones, pero limitadas y selectivas, determinadas con aplicación de los criterios indicados, que inevitablemente conducirán a desechar planteamientos anteriores, reivindicaciones históricas, incluso compromisos que, desfasados, resultan anacrónicos y carecen de viabilidad. Tal estrategia reclama como directriz de actuaciones un Plan Nacional de Modernización de Regadíos, cuyas líneas maestras han sido ya esbozadas por el Instituto de Reforma y Desarrollo Agrarios.

La superficie a mejorar, por uno o varios conceptos, ha sido estimada en 1.823 .507 hectáreas, es decir, el $55 \%$ del regadío actual, privando en el $28 \%(963.507$ ha) mejoras ambientales y estructurales en el resto (860.000 ha), con el reparto geográfico contenido en el CUADRO 3.

\section{CUADRO 3}

Actuaciones en mejora integral y optimización de recursos

\begin{tabular}{|c|c|c|c|c|c|}
\hline Zona & $\begin{array}{l}\text { Sup. Total } \\
(\mathrm{Ha})\end{array}$ & $\begin{array}{l}\text { Mejora medio- } \\
\text { ambiental (Ha) }\end{array}$ & $\begin{array}{l}\text { Mejora estruc- } \\
\text { tural (Ha) }\end{array}$ & $\begin{array}{c}\text { Ahorro agua } \\
\left(\mathrm{Hm}^{3} / \mathrm{año}\right)\end{array}$ & $\begin{array}{l}\text { Consolidación } \\
\text { empleo (UTH) }\end{array}$ \\
\hline España húmeda & 149.286 & - & 20.000 & -- & 5.625 \\
\hline $\begin{array}{l}\text { Valle del Ebro } \\
\text { y Cataluña Or. }\end{array}$ & 796.898 & 230.000 & 250.000 & 425 & 45.000 \\
\hline España Interior & 1.089 .081 & 180.000 & 275.000 & 350 & 35.800 \\
\hline $\begin{array}{l}\text { Mediodía y Le- } \\
\text { vante Peninsular }\end{array}$ & 1.283 .650 & 485.000 & 300.000 & 375 & 71.400 \\
\hline Archipiélagos & 68.507 & 68.507 & 15.000 & 40 & 6.500 \\
\hline Total & 3.387 .442 & 963.507 & 860.000 & 1.190 & 164.325 \\
\hline
\end{tabular}

Fuente: I.R.Y.D.A

Si a este cuadro se superpone el elaborado con vistas a las actuaciones para consolidación de regadíos, se hace bien patente que la situación más difícil la sufren, 
acompañadas por los archipiélagos canario y balear, las cuencas administrativas del Segura, Sur y Júcar, donde a la escasez de recursos superficiales se suman frecuente sobreexplotación de acuíferos, problemas de salinización, contaminación de aguas epigeas y subterráneas, amplio predominio de sistemas de riego inadecuados e infraestructuras hidráulicas obsoletas en los regadíos tradicionales, áreas donde impera, además, un minifundismo de intensa pulverización parcelaría.

La modernización de regadíos persigue como objetivos básicos, íntimamente relacionados, ahorro de agua, viabilidad económica de las explotaciones y mejora de la calidad ambiental. A ello se encaminan, con mayor o menor incidencia en cada una de las tres facetas, todo un conjunto de actuaciones, tales como:perfeccionamiento de los métodos de gestión del agua y de los procedimientos de riego, adecuada policía del agua, reutilización de retornos y residuales, reestructuración de explotaciones y parcelarios, renovación de las redes de transporte y distribución, innovaciones en las técnicas de cultivo, búsqueda de producciones competitivas y mejora de los circuitos comerciales, fomento de distintas fórmulas asociativas, prevención, control y reducción de las salinizaciones de suelos y aguas, intensificación de la lucha contra la contaminación difusa y de acuíferos, protección del entorno natural y de la biodiversidad, respeto del caudal ecológico, defensa y preservación de zonas húmedas, eliminación de la sobreexplotación de mantos freáticos, recarga de acuíferos, más y mejor regulación de los caudales fluviales y adecuada formación de los regantes.

Las actuaciones encaminadas al afianzamiento, modernización y mejora de regadíos inciden, con casuística muy varia, en tres niveles: la propia parcela, la organización de riego en que se halla inserta y, por último, los diversos aspectos inherentes a la consecución del agua. En cualquiera de esos tres planos las actuaciones pueden ser muy diversas, más o menos complejas, intensas y acumulativas.

Así, sin pretensión alguna de exhaustividad, son posibles, entre otros, en una parcela los acondicionamientos siguientes: casi obligado resulta reemplazar el método de riego tradicional, supliendo el de inundación o el de surcos por la aspersión o el riego localizado, este último en sus modalidades, automatizadas o no, de goteo, exudación o microaspersión; se cultiva al aire libre, bajo cobertizo de plástico o en invernadero climatizado; además, las plantas pueden crecer sobre el propio suelo roturado, en otro transportado, con técnica de enarenado o en soporte de fibra de roca u otro material para el cultivo hidropónico. Por supuesto, las inversiones son también muy diferentes, ya que pueden ir de las 50.000 ptas/ha en adaptaciones muy elementales a costes mil veces superiores en las instalaciones más complejas y sofisticadas. 
Otras intervenciones afectan al conjunto del regadío, mediante renovación del las redes de transporte y distribución primaria, informatización del proceso, policía del agua, gestión del riego, formación de regantes y gestores, y reestructuración de explotaciones y parcelarios. Por último, es de subrayar que las disponibilidades de agua difieren mucho de unas áreas a otras. En los casos más favorables se cuenta con un suministro que, salvo sequías extremadamente intensas, queda garantizado por concesiones muy generosas. Como contrapunto, en los regadíos deficitarios dotaciones escasas e irregulares constituyen denominador común, con secular demanada de transferencia de recursos foráneos; dicha caracterización conviene por entero a los regadíos tradicionales del sureste ibérico dependientes históricamente de los módulos exiguos y harto irregulares de los ríos-rambla (GIL OLCINA, 1993 a). Regadíos precarios más recientes, con origen en el aprovechamiento de sobrantes y retornos, tropiezan hoy con serias dificultades por la reducción creciente de los primeros y la intensa contaminación de los segundos; buena muestra de ello proporcionan las casi 50.000 hectáreas transformadas con elevación de sobrantes del Segura y de aguas muertas de sus azarbes (GIL OLCINA, 1993 b). Resaltemos igualmente la situación angustiosa de nuevos regadíos donde la movilización excesiva de recursos subterráneos ha originado sobreexplotación de acuíferos, con la serie de secuelas ya aludidas, en particular los procesos de salinización; de destacar es asimismo el grave problema que representa el deterioro de mantos freáticos por la contaminación difusa de procedencia agrícola.

En sus páginas introductorias, el borrador del Plan Nacional de Modernización de Regadíos elaborado por el Instituto de Reforma y Desarrollo Agrarios enfatiza que "la modemización del regadío cumplimenta y desarrolla acertadamente la política estructural de Ia Lnión Europen, así como la política socioestructural de la PAC, dado que en pocas áreas comunitarias de la extensión y singularidad climática de nuestro pats, puede hablarse, con mayor acierto, de la necesidad de medidas específicas en favor de determinadas regiones con caracteristicas agrarias especiales y mediante prácticas agrarias compatibles con el medio ambiente en zonas ecológicamente sensibles".

La mejora ambiental de nuestros regadíos exige la solución de dos tipos de problemas: los que padece el regadío por insuficiencia y mala calidad de las aguas, condicionantes negativos con frecuencia coincidentes; y los que origina el propio regadío, traducidos, sobre todo, en menoscabo de acuíferos, suelos, cursos fluviales y zonas húmedas. Para prevenirlos y subsanarlos se requiere una amplia gama de acciones, que incluye: rigurosos estudios hidrológicos y de impacto ambiental, inventarios precisos de los recursos de agua y ordenación de los mismos, regulaciones legales, depuración de residuales, instalación de plantas desaladoras, trasvases, nuevas tecnologías de riego y producción agraria, explotación racional de aguas epigeas y subterráneas, recarga de acuíferos, prevención de la contaminación difusa y 
corrección del deterioro de freáticos y suelos. Se trata, en suma, de conseguir una integración armoniosa del regadío en el medio natural, mediante adecuación de los existentes y exigente planificación de las nuevas transformaciones.

Ya en 1966 el Informe FAO-BIRD sobre Desarrollo de la Agricultura Española planteaba la necesidad de una evaluación rigurosa de los proyectos de transformación en regadío. Con posterioridad, la adhesión española a la Comunidad Europea, el reciente acuerdo GATT y la reforma de la PAC constituyen marco de referencica obligado, donde esta última ubica muy destacados los objetivos de conservación de la naturaleza y atenuación del impacto ambiental de las actividades agrarias.

En esta misma línea, el Ministerio de Agricultura, Pesca y Alimentación ha propuesto, en 1995, una revisión en profundidad, con criterios técnicos, sociales, económicos y de impacto ambiental, de la política de nuevos regadíos, sin perjuicio de que considere urgente la consolidación de la agricultura de las regiones mediterráneas y meridionales, $y$, en consectencia, estime necesaria la aprobación del Plan Hidrológico Nacional para que, previos los oportunos trámites, puedan acometerse los trasvases. Y añade que la política de regadíos constituye parte básica del Desarrollo Rural, pero no su único instrumento. Así, pues, las áreas o comarcas donde resulten incumplidos compromisos históricos de transformación en regadío, a causa de la inviabilidad técnica, social, económica o ambiental de la misma, habrán de ser compensadas con programas específicos de Desarrollo Rural Sostenible. Estos pueden crear o potenciar fuentes considerables de ingresos mediante el fomento de una serie de actividades, tales como: sistemas de agricultura extensiva auspiciados por la actual Política Agraria Común, agricultura biológica, industrias agroalimentarias, revitalización de producciones artesanales, protección de espacios naturales, reforestación, recuperación del patrimonio histórico-artístico, turismo rural, caza y otras prácticas deportivas, así como distintas posibilidades en el marco de planteamientos asociativos.

\section{BIBLIOGRAFÍA}

BURDALO, S. y DELGADO, C. (1987): "La sal de la tierra", Revista M.O.P.L., nº 320, pp. 32-33.

CALVO GARCIAA-TORNEL, F. (1988): "Explotación y problemática de los acuíferos subterráneos", en Denanda y Economia del Ağua cn España, Alicante.

CANO GARCÍA, G.M. (1993): “Transformaciones agrarias y ordenación del territorio en Andalucía", en Medio siglo de cambios agrarios en España, Instituto Juan Gil-Albert, Alicante, p. 630 .

CONFEDERACIÓN HIDROGRÁFICA DEL JÚCAR (1992): Proyecto de Directrices del Plan Hidrológico de la Confederación Hidrográfica del Júcar (policopiado), Valencia, pp. 110-112. 
CONFEDERACIÓN HIDROGRÁFICA DEL SEGURA (1992): Plan Hidrológico. Proyecto de Directrices, Murcia, pp. 63-64, 113-117 y Anejo, pp. 20-22.

CONSEJO NACIONAL DEL AGUA (1994): Informe sobre las propuestas de modificación del Anteproyecto del Plan Hidrológico Nacional, MOPTMA (documento policopiado, 20-VII-1994).

DIRECCIÓN GENERAL DE DESARROLLO AGRARIO (1991): Plan de Modernización de los regadíos tradicionales de Mula, Consejería de Agricultura, Ganadería y Pesca de la Región de Murcia, Compobell, Murcia.

DIRECCIÓN GENERAL DE PLANIFICACIÓN RURAL Y DEL MEDIO NATURAL (1995 a): Avance del Plan Nacional de Regadios (Borrador 03), M.A.P.A.

DIRECCIÓN GENERAL DE PLANIFICACIÓN RURAL Y DEL MEDIO NATURAL (1995b): Avance del Plan Nacional de Regadios, M.A.P.A. (documento policopiado, octubre 1995).

FRUTOS MEJIAS, L. Ma. (1993): "Los cambios en la agricultura de regadío aragonesa (19501990)", en Medio siglo de cambios agrarios en España, Instituto "Juan Gil-Albert", Alicante, p. 795.

GIL OLCINA, A. (1989): "Aridez, riego localizado y agricultura de vanguardia en el litoral murciano de Aguilas", en Los Paisajes del Agua, Universidades de Valencia y Alicante, pp. $213-222$

GIL OLCINA, A. (1993 a): La propiedad de aguas perennes en el sureste ibérico, Universidad de Alicante, Alicante, $191 \mathrm{pp}$.

GIL OLCINA, A. (1993 b): "El déficit de agua y sus limitaciones al crecimiento actual de la provincia", en Estructura Económica de la Pronincia de Alicante, pp. 110-111.

GIL OLCINA, A. (1995): "Conflictos autonómicos sobre trasvases de agua en España", Investignaciones Geograficas, $\mathrm{n}^{\circ} 13$, Instituto Universitario de Geografía, Universidad dé Alicante, Alicante, pp. 17-28.

INSTITUTO DE REFORMA Y DESARROLLO AGRARIOS (1995): Plan Nacional de Modemización de Regadíos (Borrador), M.A.P.A. (documento policopiado, febrero 1995), pp. 13.

LLAMAS MADURGA, R. (1986): "Las aguas subterráneas y la ingeniería de caminos en las dos últimas décadas", La Voz dol Colegiado, n 84, Colegio de Ingenieros Técnicos.

MARCHENA GÓMEZ, M. (1988): "Agua y turismo en la Andalucía mediterránea", en Demanda y Economía del Agua en España, Instituto Universitario de Geografía, Universidad de Alicante, Alicante, pp. 101-114.

MARTÍN GALINDO, J.L. (1988): Almería, Paisajes Agrarios, Espacio y Sociedad, Universidad de Valladolid, Valladolid, 499 pp.

MELGAREJO, J. (1995): La intervención del Estado en la Cuenca del Segura, Instituto Juan GilAlbert, Alicante.

MIRA CANOVAS, F. (1976): "Importancia y significación de las aguas subterráneas para Villena", Día de la Pinuincia, I.D.E.A., pp. 71-82. 
MOLINERO HERNANDO, F. (1993): "Transformaciones agrarias en las llanuras sedimentarias de Castilla y León", en Medio sigrlo de cambios agrarios en España, Instituto Juan Gil-Albert, Alicante, pp. 358-359.

MORALES GIL, A. (1995): "Escasez y rentabilidad del agua en el sureste de España: agricultura de vanguardia", en Metio Ambiente y Ordenación del Territorio, Fundación Duques de Soria, Universidad de Valladolid, pp. 82-99.

MORALES GIL, A. y RICO AMORÓS, A.M. (1996): "Sequías en el sureste de la Península Ibérica: cambios en la percepción de un fenómeno natural", Investigaciones Geográficas, no 15, pp.127143.

NAREDO PÉREZ, J.M., LÓPEZ GÁLVEZ, J. y MOLINA HERRERA, J. (1993): “La gestión del agua para regadío. El caso de Almería", El Boletín (M.A.P.A.), n 9, pp. 16-20.

PARRONDO, J. (1987): "Pozos sin fondo", Revista M.O.P.Ul, n 341, pp. 16-21.

PÉREZ PUCHAL, P. (1967): "Los embalses y el régimen de los ríos valencianos", Estudios Geográficos, ${ }^{\circ}$ 107, Universidad de Valencia, pp. 149-196.

PORCEL, MaC. y LARA VALLE, J.J. (1988): "El regadío en el Campo de Nijar", en Demanda y Economia del Agua en España, Alicante, Instituto Universitario de Geografía, pp. 339-350.

RAMÓN MORTE, A. (1994): La tecnificación del regadío valenciano, M.A.P.A., Serie Estudios n 85, Madrid.

RICO AMORÓS, A.M. (1994): Sobrexplotación de aguas subterráneas y cambios agrarios en el Alto y Medio Vinalopo (Alicante), Instituto Universitario de Geografía, Universidad de Alicante e Instituto de Estudios Juan Gil-Albert, Alicante, p. 276.

RODRÍGUEZ BRITO, W. (1995): El agua en Canarias y el siglo XXI, Cabildo Insular de Gran Canaria, Las Palmas.

RODRÍGUEZ ESTRELLA, T. (1986): "Las aguas subterráneas de la Comunidad Valenciana", El Campo, n 103 , pp. 32-43.

RODRÍGUEZ ESTRELLA, T. (1987): "Principales características geológicas e hidrogeológicas de la región de Murcia", El Campo, no 105, pp. 26-32.

TIÓ SARALEGUI, C. (1995): "La política del Plan Nacional de Regadíos", El Boletín, M.A.P.A., n” 24, pp. 6-12. 